\title{
Cartografía social pedagógica: entre teoría y metodología*
}

Revista Colombiana de Educación, N. ${ }^{\circ} 70$. Primer semestre de 2016 Bogotá, Colombia.

\section{//Social Pedagogical Carthography: \\ Between Theory and Methodology}

\section{//Cartografia social pedagógica: entre teoria e metodologia}

\begin{abstract}
Recibido: 15/01/2015 Evaluado: 21/02/2015

Diego Fernando

Barragán Giraldo**

$11 / 05 / 2015$

$09 / 06 / 2015$ $23 / 06 / 2015$
\end{abstract}

\section{Resumen}

El presente artículo presenta los resultados de un ejercicio investigativo de corte cualitativo en el que, a partir de la experiencia de profesores en ejercicio que cursan estudios de maestría en Educación, se aporta a la configuración del corpus teórico y metodológico de la cartografía social pedagógica (CSP). Con base en lo acontecido y observado en catorce talleres y las narraciones de los profesores en cuestión, se presentan ciertas particularidades de la CSP y se proponen algunas rutas comprensivas que evidencian las coincidencias y distancias con la cartografía participativa y la cartografía social. Además, la investigación permitió validar una propuesta de realización de CSP.

\section{Abstract}

The article presents the results of qualitative research which, from the experience of teachers enrolled in graduate education studies, contributes to the configuration of the theoretical and methodological corpus of educational social mapping [cartografía social pedagógica (CSP)]. Based on what happened and what was observed in fourteen workshops and feedback from the teachers involved, some particularities of the CSP were presented and some comprehensive routes that highlighted the similarities and differences between participatory and social mapping were proposed. Moreover, the investigation allowed the proposal of actualizing the CSP to be validated.

\section{Resumo}

O seguinte artigo apresenta os resultados dum exercício investigativo de corte qualitativo no que, a partir da experiência de professores em exercício que cursam estudos de Mestrado em Educação, aporta-se à configuração do corpus teórico e metodológico da cartografia social pedagógica (CSP). Com base no acontecido e observado em catorze oficinas e as narrações dos professores em questão, apresentam-se algumas particularidades da CSP e propõem-se algumas trilhas compreensivas, que evidenciam as coincidências e distâncias com a cartografia participativa e a cartografia social. Além disso, a pesquisa permitiu validar uma proposta de realização de CSP.

\section{Palabras clave}

Cartografía social pedagógica, cartografía participativa, cartografía social, investigación cualitativa, metodología de la investigación

\section{Keywords}

Socio-pedagogical Cartography, Participative Cartography, Social Cartography, Qualitive research, Research methodology

\section{Palavras chave}

Cartografia social pedagógica, cartografia participativa, cartografia social, pesquisa qualitativa, metodologia da pesquisa 
El ser humano ha intentado representar el mundo circundante por medio de diversas formas creativas: narraciones, arte, escritura, fotografía, entre otras tantas; en esta amalgama de posibilidades, los mapas suelen ser una producción humana en la que se intenta comprender lo circundante ya sea en relación con la geografía o con lo que está más allá de lo terreno. Es probable que la creencia de los filósofos presocráticos, en la que se concebía a la tierra como un disco flotante, provenga de la tradición cultural y de los textos sagrados de civilizaciones ribereñas como la mesopotámica y la egipcia (Kirk, Raven, \& Schofield, 2014, p. 32). Esta alusión sobre la configuración geográfica del mundo conocido tuvo sus primeras manifestaciones sistemáticas en la filosofía de Tales de Mileto, de quien Aristóteles dice que el milesio creía que la tierra está sobre el agua (Metafísica, II, 983, b6)ํ. También se afirma que "Anaximandro de Mileto, discípulo de Tales, fue el primero que se atrevió a dibujar la tierra habitada sobre una tablilla; después de él, Hecateo de Mileto, viajero incansable, perfeccionó la carta, hasta el punto que llegó a ser motivo de admiración" (Agatémero, 1, 1). Por su parte, Heródoto dice que "los griegos adquirieron de los babilonios el conocimiento de la esfera celeste" (Heródoto, II, 109) y pone en duda las cartas del mundo conocido, tal vez las jonias: "Me río al ver que muchos, hasta la fecha, dibujaron contornos de la tierra y que ninguno desarrolló sensatamente: dibujan a Océano fluyendo en torno a la tierra, a la que pintan circular, como hecha a compás, y hacen a Asia igual a Europa" (Heródoto, IV, 36).

Este interés de los griegos por mapear el mundo deja entrever la importancia que ha tenido poder hacer una representación de lo terreno y supraterreno, como en el caso de la observación astronómica o los mapas geográficos. Y aun cuando la realización de cartas geográficas ha sido un asunto de no poca importancia en la historia, estas solo tienen valor en la medida en que las pueden interpretar diferentes personas al poder decodificar aquello que quien las realizó deseó plasmar. En consecuencia, aquello que se refleja en tales mapas es una representación del mundo geográfico y comúnmente se asumen como "espejos, representaciones gráficas de algunos aspectos del mundo real [...] y que el papel del mapa es de presentar una imagen factual de la realidad geográfica" (Harley, 2005, p. 73); realidades que pueden comprenderse de 
acuerdo con las representaciones socioculturales de quien realiza el gráfico y de quien lo lee; es decir, lo que se representa es un sistema relacional de comprensión del mundo. Ahora bien, aun cuando esta manía humana de mapear es antigua y los griegos ya lo hacían sistemáticamente "sólo hasta el siglo XIX apareció el término cartografía, acuñado por el historiador portugués Manuel Francisco de Barros y Sousa" (Montoya, 2007, p. 157).

En todo caso, los mapas evidencian la hegemonía de ciertos modelos de comprensión del mundo, pues aun cuando se intente mostrar cómo es realmente la tierra (como el caso de la fotografías satelitales o la ubicación mediante el sistema de posicionamiento global, GPs por sus siglas en inglés), siempre se evidencian las tensiones económicas y sociales de quienes diseñan los mapas al referenciar ciertas convenciones que son de utilidad para quien se guía por ellos. En el mapa del mundo se evidencian las tensiones políticas y culturales de la dominación colonial que sobrevive más allá de la ocupación territorial mediante el control económico y político que se permea en la cultura (Walsh, 2007); incluso en la actualidad tal situación sigue presentándose:

Hasta el mapa miente. Aprendemos la geografía del mundo en un mapa que no muestra el mundo tal cual es, sino tal como sus dueños mandan que sea. En el planisferio tradicional, el que se usa en las escuelas y en todas partes, el ecuador no está en el centro, el norte ocupa dos tercios y el sur, uno. América Latina abarca en el mapamundi menos espacio que Europa y mucho menos que la suma de Estados Unidos y Canadá, cuando en realidad América Latina es dos veces más grande que Europa y bastante mayor que Estados Unidos y Canadá. El mapa, que nos achica, simboliza todo lo demás. Geografía robada, economía saqueada, historia falsificada, usurpación cotidiana de la realidad del Ilamado Tercer Mundo, habitado por gentes de tercera, abarca menos, come menos, recuerda menos, vive menos, dice menos. (Galeano E., 2003, p. 362)

Los mapas son, en definitiva, una de las formas de ejercicio de poder donde los imperios se han adueñado de los territorios, de manera tal que en el discurso cartográfico se reproduce la ideología imperante (Harley, 2005, p. 79 y ss). Así, Boaventura de Sousa Santos hablará de cartografía abismal para definir e introducir la noción de pensamiento abismal, en el que se ahonda cada vez más en la radicalidad dicotómica moderna, 
eurocéntrica en la que se agudiza la separación norte y sur, la cual desde la Colonia se instauró con vehemencia universalizando un único concepto de humanidad:

... existe, por lo tanto, una cartografía moderna dual: una cartografía legal y una cartografía epistemológica. El otro lado de la línea abismal es el reino de más allá de la legalidad y la ilegalidad (sin ley), de más allá de la verdad y la falsedad (creencias, idolatría y magia incomprensible). Juntas, estas formas de negación radical resultan en una ausencia radical, la ausencia de humanidad, la subhumanidad moderna. (Santos, 2010, p. 18)

En este contexto, la cartografía como representación de lo físico siempre está cargada de las intencionalidades políticas de su elaboración, de los horizontes ideológicos de su lectura y, a la vez, no se circunscribe al mapa que representa exclusivamente lo geográfico, sino que designa las formas de representarse aquellos espacios no visibles que se escapan a las representaciones gráficas y que permanecen en la cultura mediante la delimitación del territorio. Así, e intentando ir más allá de los mapas geográficos, aparece la cartografía social (cs) en la que, inicialmente, a partir de las consideraciones espaciales del terreno se busca que las comunidades reconfiguren la territorialidad de los espacios habitados. Esta estrategia de intervención social y de investigación cobra cada vez más fuerza en diferentes campos de indagación cualitativos ya que posibilita reconstruir representaciones del mundo físico, social y cultural para configurar rutas de transformación. De igual manera, aparece la cartografía social pedagógica (CSP), en la que se intenta trasladar ciertos aspectos de la cartografía social al campo de la educación.

\section{Mapas participativos, cartografía participativa y cartografía social (cs)}

Antes de hablar propiamente de la cartografía social vale la pena mencionar que por todo el mundo, al trabajar con comunidades rurales y urbanas, existen variadas experiencias y desarrollos teóricos de mapeo participativo (Advancement Project-Healthy City, 2012; Chambers, 2006; Fox, Suryanata \& Hershock, 2005; Hristova, Quattrone, Mashhadi \& Capra, 2013; Rambaldi, 2005; United Nations Human Settlements Programme, 2010), en los 
cuales diferentes actores intervienen en la configuración del territorio que les compete produciendo colectivamente mapas del mismo. De igual manera, la cartografía participativa (Braceras, 2012; Fondo Internacional de Desarrollo Agrícola, 2009; Habegger, 2008), que ha sido nombrada también como: "Cartografía Social indígena, contra cartografía, cartografía comunitaria, Cartografía Social, SIG participativo o mapeo comunitario" (Braceras, 2012), permite que comunidades reconfiguren sus concepciones sobre el terreno, y lleva a que estas se empoderen y decidan sobre los trascendencia social, cultural y política de su entorno:

Los mapas participativos proporcionan una valiosa representación visual de lo que una comunidad considera que es su lugar y de sus características distintivas. Abarcan descripciones de los rasgos físicos naturales, de los recursos y de los rasgos socioculturales conocidos por la comunidad [...] El proceso de Cartografía Participativa puede influir en la dinámica interna de una comunidad ya que puede contribuir a cohesionar la comunidad, a estimular a sus miembros a intervenir en la adopción de decisiones sobre la tierra, sensibilizar en torno a los problemas apremiantes relacionados con la tierra $y$, en último término, contribuir al empoderamiento de las comunidades locales y de sus miembros. (Fondo Internacional de DesarroIlo Agrícola, 2009, p. 4)

Los alcances de la cartografía participativa permite pensar en las posibilidades comunitarias más allá de las cartografías oficiales en las que las narraciones gráficas delimitan las subjetividades; esta opción alternativa, que algunos investigadores asocian con la investigación-acción participativa (IAP), cobra especial relevancia en los trabajos con comunidades y posee ciertas particularidades que la vinculan con la participación y la transformación (véase la tabla 1). 
Tabla 1. Criterios para identificar y denotar mapas participativos en la cartografía participativa

\begin{tabular}{l|l}
$\begin{array}{l}\text { La cartografía par- } \\
\text { ticipativa se define } \\
\text { por el proceso de } \\
\text { producción. }\end{array}$ & $\begin{array}{l}\text { Los mapas participativos se planean en torno a un objetivo } \\
\text { realizan con aportaciones de toda una comunidad en un } \\
\text { proceso abierto e incluyente. Cuanto mayor sea el nivel } \\
\text { de participación de todos los miembros de la comunidad, } \\
\text { más beneficioso será el resultado, porque el mapa final } \\
\text { reflejará la experiencia colectiva del grupo que lo haya } \\
\text { producido. }\end{array}$ \\
\hline $\begin{array}{l}\text { La cartografía par- } \\
\text { ticipativa se define } \\
\text { por un producto } \\
\text { que representa } \\
\text { el ideario de la } \\
\text { comunidad. }\end{array}$ & $\begin{array}{l}\text { La producción de mapas se lleva a cabo por comunidades } \\
\text { para mostrar información que es pertinente e importante }\end{array}$ \\
para sus necesidades y que está destinada a su uso.
\end{tabular}

Por otra parte, sin desconocer la similitud con muchos elementos de la cartografía participativa, se puede decir que la particularidad de la cartografía social radica en que también es una opción metodológica para aproximarse a las comprensiones sobre el territorio que un conjunto de seres humanos poseen de él. De esta manera, el levantamiento del mapa (cartografía) no se circunscribe a la delimitación de los espacios físicos, sino que se ancla a las diversas tensiones que emergen de las relaciones socioculturales de quienes habitan el territorio en cuestión. Importa en esta estrategia el que los diferentes actores lleguen a acuerdos sobre las interpretaciones que emergen de las problemáticas socioculturales que se evidencian en el territorio, de forma tal 
que, como colectivo, puedan tomar decisiones de transformación de sus prácticas. Algunos autores relacionan esta estrategia cartográfica con la investigación-acción participativa (IAP), por el carácter dinámico de la configuración del mapa y los acuerdos de actuación que surgen del trabajo colectivo en el que se dialoga sobre las problemáticas que el mapa evidencia, que llevan al empoderamiento de los participantes. Así, la Cs remite a fijar las miradas en las prácticas, no solo en el plano instrumental, sino que las vincula con los aspectos éticos, morales, axiológicos y políticos del hacer cotidiano de quienes participan del mapeo.

Ahora bien, la cs como propuesta novedosa "de investigación humanista y humanizadora" (Habegger, Serrano, \& Mancila 2006) se ha utilizado en el ámbito de la investigación, intervención y acompañamiento social. Este tipo de cartografía permite que las diferentes comunidades se empoderen de sus espacios territoriales, para transformar las propias realidades; por ello, algunos investigadores entienden que "el objetivo de la Cartografía Social es comprender mejor el territorio y consolidar un sentido de pertenencia" (Centro de Estudios Sociales, 2011, p. 8) pero su base sigue siendo la referenciación geográfica donde acontecen las relaciones sociales. Así, elementos del paisaje social y cultural, como ríos, casas, cultivos, parques, mercados y lugares donde acontecen las relaciones productivas, sociales, amistosas, amorosas, violentas, por citar algunos aspectos, son relacionados por quienes dibujan el mapa ${ }^{2}$. No obstante, más allá de la representación física, aquello que llega a parecer en la cs son las "relaciones de etnicidad, identidades compartidas, que acontecen en un determinado territorio y que se perpetúan transformándose en la cultura e interacción de los individuos" (Gabbert, 2006), por lo que es necesario reconfigurar la concepción tradicional de mapa.

Con este marco de referencia vale mencionar que la cs gradualmente ha conformado un campo de interpretación de la realidad, en el que a nivel investigativo y de intervención se configuran los procesos de subjetivación e identificación de diversos grupos humanos en relación con su territorio y lo que allí acontece. A manera de antecedentes, y solo por citar algunos procesos de intervención e investigación en los que se ha utilizado la Cs, pueden mencionarse las siguientes experiencias: comunidades afrodescendientes en Colombia que llegan a reconocer y defender la importancia de la pertenencia de la tierra, en la medida en que se exploran sus territorios y se subjetivan políticamente para tomar decisiones, dialogar y exigir sus derechos ante instancias gubernamentales o no gubernamentales (Vélez, Rátiva \& Valera, 2012). Procesos en los que se ha levantado información valiosa

2 Los mapas pueden ser creados por los participantes o utilizar aquellos preestablecidos, también se pueden utilizar fotografías satelitales o sistemas de georreferenciación por medio de GPS. 
sobre la vulneración de los derechos humanos por parte de grupos armados o sociedad civil, en comunidades ancestrales americanas en el departamento del Meta, Colombia (Vicepresidencia de la República, 2010). Pueblos originarios americanos que en el actual Brasil pueden exaltar sus voces para evidenciar la importancia de su territorio y la incidencia de las políticas económicas, sociales y ambientales que los afectan (Berno de Almeida \& Acevedo, 2010; Movimento Interestadual das Quebradeiras de Coco Babaçu, 2005; Sampaio, 2012). Zonas urbanas en las que se resignifica el concepto de "barrio" en sus tensiones de poder y las dinámicas productivas (Hallak \& Barberena, 2012; Montoya, 2007; Montoya, García, \& Ospina 2013); también, vinculación de las comprensiones sobre la ciudad desde la participación juvenil (Alcaldía Mayor de Bogotá D. C., 2008) y la familiarización de estudiantes universitarios con el trabajo de campo al mapear la ciudad mediante un levantamiento cartográfico en la localidad de Suba en Bogotá (Osorio \& Rojas, 2011). La pertenencia de una comunidad alrededor de la problemática de las basuras y sus propuestas de transformación (Escudero, 2012; Vázquez \& Massera, 2012). Estrategias de reubicación urbana de comunidades en situación de riesgo (Quiñónez, 2011) y de configuración de la Geomática (Mora-Páez \& Jaramillo, 2004). Policías en ejercicio y otros actores sociales que comprenden las tensiones sobre violencia intrafamiliar (García, 2012). Temas sobre género en educación (Stromquist, 2006). La vinculación de diferentes actores con una facultad de ciencias en Uruguay (Álvarez et al., 2011). La forma como la cs permitió pensar los espacios geográficos mediante los sistemas de información geográfica (SIG) vinculando tecnologías de información y comunicación (TIC) para la enseñanza de ciencias sociales en una escuela rural de Colombia (Bernal \& Galindo, 2012). La configuración de los momentos de los procesos con enfoque de investigación-acción participativa (IAP) (Braceras, 2012; Habegger, 2008; Valderrama, 2013). Presentación de una metodología en Colombia para la elaboración de mapas de vulnerabilidad, riesgo y oportunidades que permitan identificar los factores que inciden en la vinculación de niños, niñas y jóvenes a grupos armados ilegales y los factores protectores en sus contextos más cercanos (Organización Internacional para las Migraciones, 2009).

Ahora bien, en toda cartografía la comprensión que se tenga del concepto territorio es fundamental. En el caso de la cs este se entiende como un conjunto de interacciones sociales que pueden ser captadas discursivamente y determinan los lugares de 
convivencia de los individuos, más allá del orden natural, permitiendo que estos se configuren como sujetos de la acción social; en el territorio se dan las tensiones de poder y las lógicas de resistencia:

El territorio construye subjetividad y es construido desde ella. Lo territorial es memoria, recuerdos y "previsiones extrañas" poseyendo también diversas posibilidades de acceso a la multiplicidad de imágenes, representaciones, imaginarios $y$ sentidos que trasciende a la realidad objetiva desde fisonomías que cambian a partir de innumerables expresiones [...] El territorio, de esta manera puede ser entendido como una construcción social que se desarrolla a partir de las significaciones y usos que los sujetos construyen cotidianamente, a partir de historias comunes, usos y sentidos. Así como sujetos somos seres con historia, el territorio también la tiene y esa historicidad es construida en forma colectiva. (Carballeda, 2012, p. 28)

Así entendido, el territorio ya no es simplemente la localización de un grupo humano en un lugar específico, sino que remite a la presencia existencial de un conjunto de habitantes del mismo; el territorio se habita y esa acción de presencialidad remite a la configuración de ciertos territorios existenciales, que derivan en conceptualizaciones del orden sociocultural. Sin embargo, tal como Guattari (2000) lo propone, el detrimento de los territorios existenciales por la exacerbación de la producción de bienes materiales ha llevado a un inmenso vacío de la subjetividad ( $p$. 40); se trata, en palabras del filósofo, de ritornelos existencialistas, que son modos de producción de subjetividad y universos incorporales que cristalizan "territorios existenciales más desterritorializados. Este tipo de ritornelo transversalista escapa a una delimitación espacio-temporal estricta" (Guattari, 1996, p. 29).

\section{Cartografía social pedagógica (CSP)}

Romper con el pensamiento positivista que ha imperado durante los últimos siglos, implica nuevas formas de configuración de la subjetividad en relación con las tensiones éticopolíticas en las que los seres humanos nos insertamos en el mundo mediante prácticas de diverso orden (Barragán, 2012, 2013); desde esta perspectiva, las rupturas epistemológicas y metodologías de indagación social son una necesidad, para así encontrar otras formas de comprensión sobre lo humano. Tal como se ha mostrado líneas atrás, la cs se ha convertido en uno de esos puntos de fuga donde se va más allá de lo instituido por la lógica moderna de comprensión del mundo: 
[... ] reconocer al mapa como un mensaje social, implica una labor de descomposición de la retórica y las metáforas cartográficas, y un alejamiento del pensamiento positivista para adentrarse en la teoría social, prescindiendo por principio de la neutralidad y la objetividad con que se ha revestido hasta ahora el saber científico. (Diez Tetamanti, 2012, p. 15)

En este contexto, el mapa, como mensaje social, no remite exclusivamente a un lugar físico, sino que bien puede entenderse como abstracción que sirve para situarse en el mundo; es decir, como la expresión de diversos modos de subjetivación por los que el ser humano habita su propia existencia. Por lo anterior y teniendo en cuenta que la mayoría de experiencias de cartografía social poco abordan el tema educativo, en un trabajo anterior (Barragán \& Amador, 2014) hemos propuesto asumir algunos principios de la cartografía social y ponerlos en juego en el campo de la educación, con miras a dinamizar la investigación educativa y promover niveles de acción didáctica de los diferentes actores que intervienen en los procesos de enseñanza-aprendizaje. Así, la cartografía social pedagógica (CSP) es una posibilidad para ir más allá de lo tradicionalmente instituido y es una vía efectiva para transformar la educación. La CSP se puede entender como una estrategia de investigación y acompañamiento en la que, por medio de la acción colectiva, se lleva a los participantes a reflexionar sobre sus prácticas y comprensiones de una problemática común, mediante el levantamiento de un mapa (cartografía) en el que se evidencian las problemáticas que acontecen en dicho territorio; en este caso, los territorios relacionados con las tensiones de las prácticas de enseñanza y de aprendizaje. La finalidad de la CSP va más allá de la representación gráfica de los territorios donde acontecen las acciones educativas; implica vincular a los participantes en la posibilidad de transformar sus prácticas; se fortalecen lazos de cooperación y se fortifica el aprendizaje entre pares ${ }^{3}$. Para lograr lo anterior y desarrollar CSP se han de tener en cuenta los siguientes elementos: el mapa,

3 La csp puede llevar a que los aprendizajes sean más efectivos, especialmente cuando hay un reconocimiento del otro como un ser capaz de humanidad; es decir, los participantes se pueden reconocer como pares y entre todos llegar a construir horizontes comunes de actuación. Esta subjetivación entre pares cobra especial valor cuando se llega a crear comunidades de práctica en las que se produce conocimiento y se transforman las acciones concretas de individuos y colectividades (Barragán, 2015). 
el territorio, el sistema de relaciones y las acciones-relaciones (Barragán \& Amador, 2014). A continuación un breve desarrollo de los conceptos.

\section{El mapa}

En la cSp el mapa se concibe como una representación gráfica que, realizada en colectivo, deja ver las tensiones socioculturales que surgen en determinado territorio físico donde suceden situaciones de enseñanza y aprendizaje (aula, escuela, barrio, ciudad, ciberespacio, etc.). Sin embargo, el mapa también puede expresar un territorio epistemológico o uno existencial, en estos casos aquello que aparece son las abstracciones constituidas en colectivo, en las que se resignifican las comprensiones de diversos temas educativos y pedagógicos, los cuales deben plasmarse cartográficamente a partir de las experiencias de los participantes $y$, si es el caso, de la teoría educativa. Como producto discursivo, el mapa evidencia la subjetivación de los participantes de la CSP. Se pueden enunciar tres tipos de mapas que logran ser punto de partida para explorar las posibilidades de esta opción metodológica (Barragán \& Amador, 2014): el ecosistémico-poblacional, que se refiere a relaciones territoriales; el temporal-social, en el que se exploran las tensiones de pasado, presente y futuro; $y$ el temático, que configura las problemáticas y la planificaciones concretas (véase la figura 1).

\section{El territorio}

Como se ha mencionado, el territorio sobrepasa los límites físicos. En su aproximación a la constitución de la subjetividad y a la configuración de una cartografía ecosófica, Guattari $(1996,2000)$ ha propuesto hablar de "Territorio Existencial más que de instancias del yo y de transferencia" (Guattari, 1996, p. 153). En este orden de ideas, el territorio existencial alude a las diferentes maneras en que la existencia humana hace presencia en diversas formas narrativas y que se materializa en ciertos límites que identifican a los habitantes de esa esfera narrativa. En la CSP el territorio se delimita, representa y plasma en el mapa; allí, los territorios son múltiples, diversos y pueden cohabitar de modos extraños. Por ello, el territorio solo existe en la medida en que aparecen los actores que lo habitan y, en consecuencia, hacen existir aquello que el mapa evidencia ${ }^{4}$. El territorio es la existencia misma, la cual se expresa en el arraigo y permite que la subjetividad emerja: "el territorio es la vida dijo en algún momento del ejercicio (cartográfico) un participante indígena del municipio de Mapiripán" (Vicepresidencia de la República, 2010, p. 109). Así, en la CSP los territorios pueden tener una connotación física o se puede llegar

4 Sin forzar el discurso, estas relaciones se acercan al concepto de campo de Bourdieu, el cual existe solo en la medida en que se juega el juego y se conforma el habitus relacional de quienes están actuando en el campo. 
hablar de un territorio epistemológico, en el que se esquematizan las condiciones de producción de las concepciones sobre educación que los participantes comparten con base en sus propias experiencias y sus presupuestos teóricos. En todo caso, trátese de territorios fiscos o epistemológicos, en la CSP se busca, fundamentalmente, develar el carácter vivencial de los mismos, es decir: territorios existenciales.

\section{El sistema de relaciones}

En la CSP, mapa y territorio son importantes siempre y cuando dejen evidenciar la forma como se dan las relaciones y sus respectivas tensiones. Comprender las tensiones que emergen en las relaciones sociales es uno de los ejes importantes de toda construcción colectiva de los mapas. Ahora bien, en la csp este elemento cobra especial relevancia al aparecer el otro como posibilidad de realización. Las relaciones se dan entre seres humanos, en consecuencia, lo fundamental que se expresa en el mapa es la manera como individuos y colectividades se relacionan con el medio y con los otros.

\section{Acciones relaciones}

El centro de la csp es la transformación de las prácticas que involucran la enseñanza y el aprendizaje en relación con los contextos socioculturales como la política pública, las relaciones de poder, las didácticas, la socioafectividad, la teoría de la educación, la economía, la evaluación, por solo citar algunos campos de investigación. Las acciones son el centro de la vida social, estas proceden de horizontes complejos y son, por excelencia, las prácticas de los individuos que actúan en consistencia con unos espacios colectivos. Así, las acciones relaciones hacen referencia a la manera como los participantes en la CSP se empoderan de sus territorios, explicitando tales tensiones en los mapas, y se comprometen a transformaciones concretas de sus prácticas. Es en el universo del actuar donde se da la auténtica presencia territorial de los individuos que mapean su realidad, de lo contrario la CSP se queda en una simple descripción diagnóstica. 
Figura 1. Tipos de mapas recomendados en la cartografía social pedagógica (CSP)

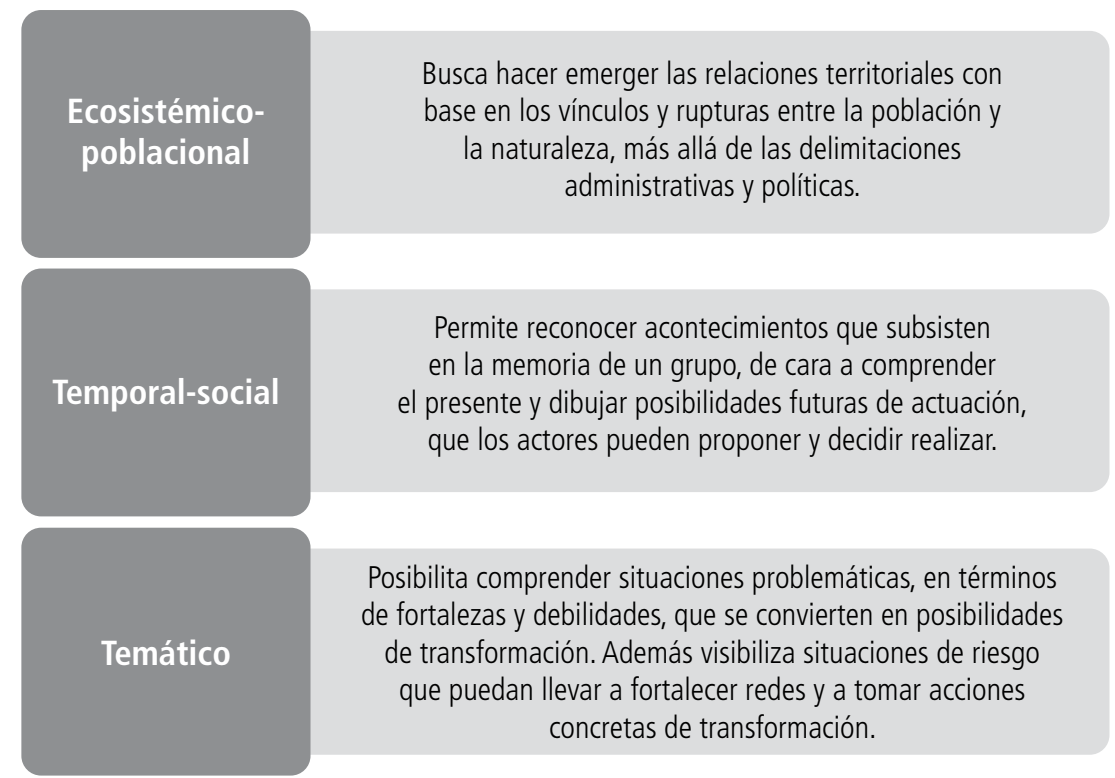

Fuente: Barragán y Amador (2014)

Sin olvidar la importancia de los tres tipos de mapas propuestos, esta investigación se apoya en el tercero: el temático. Este mapa abre nuevas fronteras y posibilidades pues permite ir más allá del territorio físico e involucrarse en lo que se ha denominado en este trabajo - agregando a la categorización inicial- el territorio epistemológico, el cual como aporte a la cartografía social invita a pensar en las formas en que podemos descolonizar los campos del saber instituidos hegemónicamente, para así constituir subjetividad. Un territorio epistemológico lleva a explorar las formas en que se han instaurado discursos omniabarcantes sobre aquello que es verdadero y posibilita comprender las condiciones de producción de conocimiento. Mapear un territorio epistemológico puede derivar en la simple enunciación teórica de aqueIlos conceptos determinantes para consolidar un campo del saber determinado. Por ello, en la CSP se ha de recurrir de manera privilegiada a la experiencia de los participantes y luego a las teorías implícitas sobre las que pueden ponerse de acuerdo.

Ahora bien, más allá del horizonte epistemológico, la acción se convierte en el centro de la CSP; allí aparece el nivel hermenéutico en la medida en que se debe centrar en las prácticas como eje de toda posible subjetivación en un territorio existencial: 
[La hermenéutica] no puede entenderse solamente como una reflexión exegética o una interpretación de textos; comprendida así, la hermenéutica quedaría reducida a la simple intelección y se disipa el sentido originario del quehacer comprensivo. La hermenéutica implica necesariamente la aplicación, de forma tal que se resignifica lo interpretativo y lo comprensivo más allá de la abstracción y la interpretación lingüística, para situar su labor en el quehacer existencial del ser humano, más allá del uso metodológico que se le suele dar en los estudios sobre lo social o sobre el ser Humano. [...] Desde esta perspectiva, el horizonte hermenéutico apunta a ir más allá de la intelección e interpretación de datos e involucra la acción misma, como eje y centro de cualquier búsqueda humana. Practicar no es en modo alguno solamente hacer cosas, es fundamentalmente aplicar; allí radica la fuerza de cualquier acción. Aplicar significa trasladar un conjunto de conocimientos del campo de la abstracción al terreno del mundo natural; es decir, implica transformar el orden natural mediante la racionalidad propia del ser humano. (Barragán, 2015, p. 164)

\section{Consideraciones metodológicas}

La investigación educativa invita a pensar rigurosamente las prácticas; no debe tratar de la conquista de la teoría sobre la práctica y busca rutas nuevas de indagación (Carr, 2004; 2007). Con el anterior presupuesto se inició este trabajo, en el que se desarroIlaron, entre marzo y noviembre de 2014, 12 talleres de cSP con estudiantes de posgrado (especializaciones y maestrías) y 2 talleres con profesores en ejercicio de la Secretaría de Educación Distrital (SED) de Bogotá; participaron 313 personas durante el proceso. Los talleres tenían como finalidad fortalecer las comprensiones de los participantes sobre las temáticas trabajadas (cursos académicos o talles de formación), para que pudiesen pensar y transformar sus prácticas. En primera instancia, el uso de la csp tenía un alcance eminentemente didáctico y pedagógico, ya que como herramienta metodológica se tenía la certeza que podía ayudar a afianzar comprensiones y vivencias. 
Tabla 2. Relación de talleres de CSP realizados

\begin{tabular}{|c|c|c|c|c|c|c|}
\hline Taller & Universidad & Programa y lugar & Curso/Taller & Fecha & Código & Participantes \\
\hline 1 & $\begin{array}{l}\text { Univ. de Bogotá } \\
\text { Jorge Tadeo Lozano }\end{array}$ & $\begin{array}{c}\text { Especialización en } \\
\text { Economía de la Salud. } \\
\text { Bogotá }\end{array}$ & $\begin{array}{c}\text { Ética y Valores } \\
\text { en Salud }\end{array}$ & $14 / 03 / 14$ & TCSP 1 & 21 \\
\hline 2 & $\begin{array}{l}\text { Univ. Santo } \\
\text { Tomás-VUAD }\end{array}$ & $\begin{array}{c}\text { Maestría en Educación. } \\
\text { Bogotá }\end{array}$ & Investigación & $29 / 5 / 14$ & TCSP 2 & 12 \\
\hline 3 & $\begin{array}{l}\text { Univ. Distrital } \\
\text {-Secretaría de Edu- } \\
\text { cación Distrital }\end{array}$ & $\begin{array}{c}\text { Proyecto Implementación } \\
\text { Ciclos de Aprendizaje. } \\
\text { Bogotá }\end{array}$ & Taller prácticas & $13 / 6 / 14$ & TCSP 3 & 32 \\
\hline 4 & $\begin{array}{l}\text { Univ. de San } \\
\text { Buenaventura }\end{array}$ & $\begin{array}{c}\text { Maestría en Ciencias de la } \\
\text { Educación. Bogotá }\end{array}$ & Investigación & $26 / 6 / 14$ & TCSP 4 & 5 \\
\hline 5 & $\begin{array}{l}\text { Univ. Francisco de } \\
\text { Paula Santander }\end{array}$ & $\begin{array}{l}\text { Maestría en Práctica } \\
\text { Pedagógica. Cúcuta }\end{array}$ & Hermenéutica & $27 / 7 / 14$ & TCSP 5 & 21 \\
\hline 6 & $\begin{array}{l}\text { Univ. Distrital } \\
\text {-Secretaría de Edu- } \\
\text { cación Distrital }\end{array}$ & $\begin{array}{c}\text { Proyecto Implementación } \\
\text { Ciclos de Aprendizaje. } \\
\text { Bogotá }\end{array}$ & Taller Prácticas & $29 / 7 / 14$ & TCSP 6 & 35 \\
\hline 7 & $\begin{array}{l}\text { Univ. de Bogotá } \\
\text { Jorge Tadeo Lozano }\end{array}$ & $\begin{array}{c}\text { Especialización en } \\
\text { Economía de la Salud. } \\
\text { Cúcuta }\end{array}$ & $\begin{array}{l}\text { Ética y valores } \\
\text { en salud }\end{array}$ & $16 / 8 / 14$ & TCSP 7 & 26 \\
\hline 8 & $\begin{array}{l}\text { Univ. de San } \\
\text { Buenaventura }\end{array}$ & $\begin{array}{c}\text { Maestría en Ciencias de la } \\
\text { Educación. Bogotá }\end{array}$ & $\begin{array}{l}\text { Cambio de } \\
\text { Paradigma }\end{array}$ & $6 / 9 / 14$ & TCSP 8 & 29 \\
\hline 9 & Univ. de La Salle & $\begin{array}{c}\text { Maestría en Ciencias de } \\
\text { la Visión }\end{array}$ & $\begin{array}{c}\text { Humanismo y } \\
\text { Ciencia }\end{array}$ & $11 / 10 / 14$ & TCSP 9 & 13 \\
\hline 10 & $\begin{array}{l}\text { Univ. de San } \\
\text { Buenaventura }\end{array}$ & $\begin{array}{c}\text { Maestría en Ciencias de la } \\
\text { Educación. Bogotá }\end{array}$ & Epistemología & $18 / 10 / 14$ & TCSP 10 & 29 \\
\hline 11 & $\begin{array}{l}\text { Univ. de San } \\
\text { Buenaventura }\end{array}$ & $\begin{array}{c}\text { Maestría en Ciencias de la } \\
\text { Educación. Bogotá }\end{array}$ & Investigación & $8 / 11 / 14$ & TCSP 11 & 12 \\
\hline 12 & Univ. Santo Tomás & $\begin{array}{c}\text { Maestría en Pedagogía. } \\
\text { Tunja. }\end{array}$ & $\begin{array}{l}\text { Tendencias } \\
\text { pedagógicas }\end{array}$ & $14 / 11 / 14$ & TCSP 12 & 16 \\
\hline 13 & $\begin{array}{l}\text { Univ. Francisco de } \\
\text { Paula Santander }\end{array}$ & $\begin{array}{l}\text { Maestría en Práctica } \\
\text { Pedagógica. Cúcuta }\end{array}$ & Hermenéutica & $17 / 11 / 14$ & TCSP 13 & 33 \\
\hline \multirow[t]{2}{*}{14} & $\begin{array}{l}\text { Univ. Francisco de } \\
\text { Paula Santander }\end{array}$ & $\begin{array}{l}\text { Maestría en Práctica } \\
\text { Pedagógica. Cúcuta }\end{array}$ & Hermenéutica & $23 / 11 / 14$ & TCSP 14 & 29 \\
\hline & & & $\begin{array}{c}\text { Total } \\
\text { participantes }\end{array}$ & & & 313 \\
\hline
\end{tabular}

Fuente: Elaboración del autor

Los 14 talleres se llevaron a cabo siguiendo la propuesta de Barragán y Amador (2014) para desarrollar CSP: a) selección del tipo de problemática, b) selección del tipo de mapa, motivación de los participantes, d) grupos de trabajo, e) acuerdo de convenciones, f) elaboración del mapa, g) explicación del mapa, h) acuerdos de transformación, i) análisis de los mapas y memoria de la cartografía. Así, al inicio de la sesión se explicaba a los participantes el sentido del ejercicio cartográfico y su alcance, y se les explicaba los pasos de su realización; de esta manera, 
se buscaba que las personas asumieran el proceso con miras al empoderamiento sobre las problemáticas de las prácticas. Todos los grupos cartografiaban sus prácticas pedagógicas con ocasión de las temáticas de los cursos o talleres y así mapeaban aquellos territorios epistemológicos y existenciales que los unían, es decir que se intentaba fomentar la pertenencia a un territorio existencial, en este caso relacionado con sus prácticas pedagógicas. Como la intencionalidad de los talleres correspondía a un interés didáctico, al terminar cada sesión se solicitó a los participantes elaborar una pequeña reflexión sobre aquello que había significado para ellos la elaboración de los mapas, haciendo especial énfasis en los aspectos colaborativos del ejercicio y, sobre todo, en las posibilidades de transformación de las prácticas; no obstante, emergieron también las opiniones de los profesores sobre su percepción de la CSP y aportes respecto a su utilización.

Ahora bien, la lectura de los mapas solo se tuvo en cuenta para el ejercicio didáctico con los participantes, en relación con el empoderamiento sobre sus prácticas; en consecuencia, el material reflexivo que se solicitó a los participantes se convirtió en el insumo principal que se plasma en este artículo y sobre el cual se desarrolló el análisis de la información, a tenor del objetivo de la investigación.

En la medida en que avanzaban los talleres, se tomó la decisión de sistematizar estas acciones en un ejercicio de investigación cualitativo que permitiera acercarse a la experiencia de los participantes con la CSP y, a la vez, avanzar en la teoría sobre esta opción metodológica. Como la mayoría de los participantes eran maestros en ejercicio y estudiaban una maestría, se asumió el siguiente objetivo: Aportar a la configuración del corpus teórico y metodológico de la cartografía social pedagógica (CSP), a partir de la experiencia de profesores en ejercicio que cursan estudios de maestría en el campo de educación.

Con este contexto y teniendo en cuenta el énfasis educativo de la CSP, se tomó la decisión de considerar solo las narraciones de 186 participantes, las cuales provenían de profesores en ejercicio que en ese momento desarrollaban estudios de maestría en el campo de la educación, quienes por la particularidad de su relación con la teoría educativa y su experiencia personal dinamizarían mejor el ejercicio investigativo. Tal decisión se tomó puesto que este grupo de maestros estaban reflexionando, en el momento, acerca de las relaciones teóricas sobre las prácticas pedagógicas. 
Figura 2. Ejemplo de mapas realizados en los talleres (TCSP 7; TCSP14)
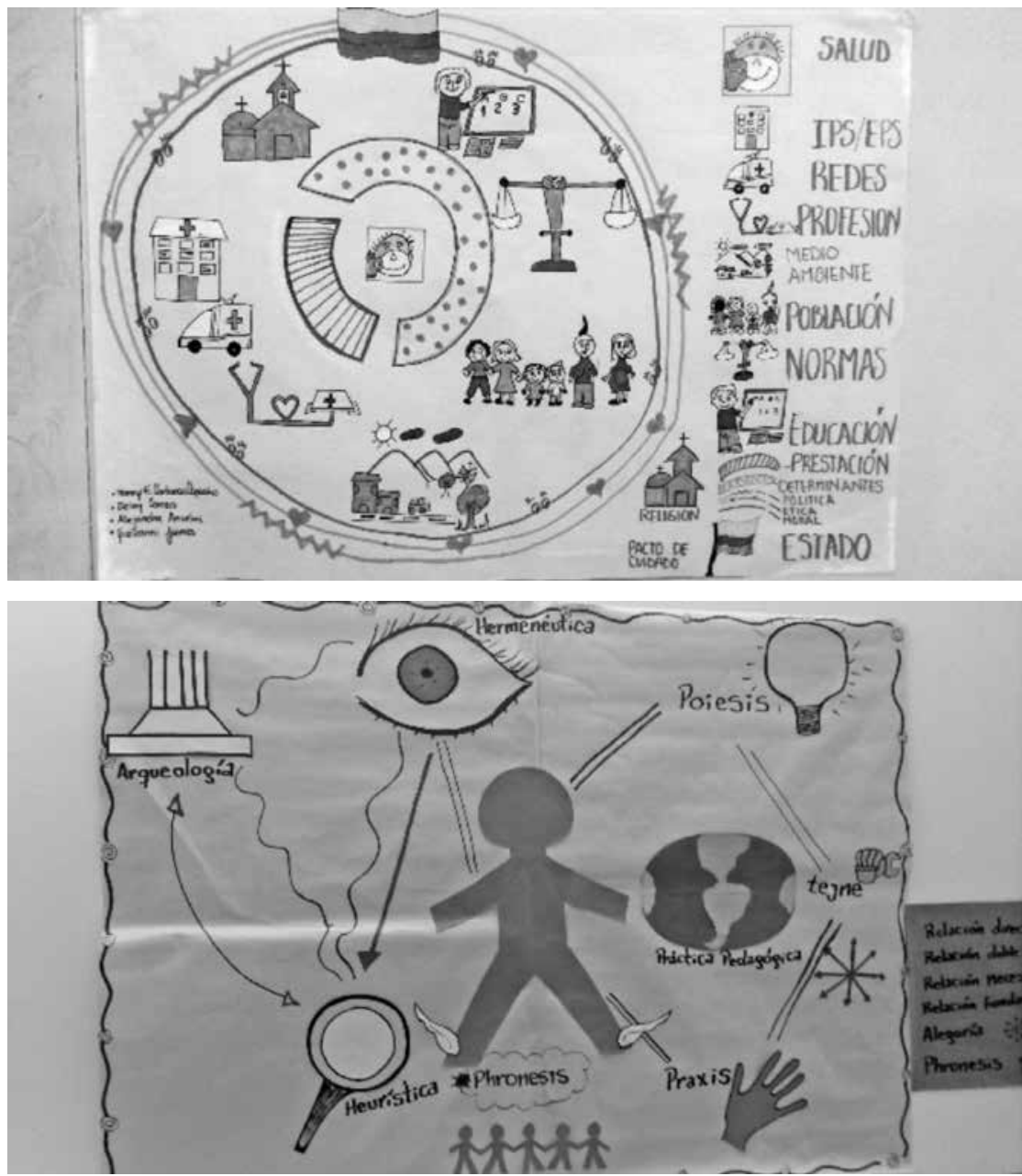

La narraciones señaladas atañen a los talleres números $2,4,5,8,10,11$, 12 , 13 y 14 (véase la tabla 2). Los demás talleres servirían para reforzar el ejercicio de validación de las pautas para realizar CSP enunciadas por Barragán y Amador (2014).

Aun cuando este no es un ejercicio propiamente de teoría fundada, se decidió no contar con categorías previas y dejar que emergieran de las narraciones, para así posibilitar la presencia existencial del discurso de los diferentes actores. Las regularidades emergentes de las narraciones permitieron configurar el marco teórico (que se presentó en la primera parte de este artículo) y profundizar en las experiencias de los participantes visibilizando su voz y aportando a la comprensión de la CSP y la teorización sobre la misma. 
Las categorías emergentes fueron: teorización sobre CSP, pertenencia a un territorio existencial, posibilidades de la CSP en investigación y pedagogía, transformación de las prácticas y experiencia vital.

Para el análisis de la información, se realizó una codificación simple asignando una nomenclatura a cada taller y sujeto dentro del mismo, por ejemplo: TCSP 5, profesora 8, donde TCSP corresponde a Taller de Cartografía Social Pedagógica y profesora 8 al lugar de la participante dentro del mismo. También se utilizaron algunos elementos de análisis de contenido (Creswell, 1997; Huberman \& Miles, 1991; Krippendorf, 1990; Navarro \& Díaz, 1999) teniendo en cuenta que esta técnica permite abordar "la estructura interna de la comunicación (composición, organización, dinámica) y el contexto en el cual se produce la información" (Galeano M. E., 2009, p. 123). Los datos se sistematizaron en una plantilla que aglutinaba las categorías emergentes.

\section{Hallazgos y discusión}

Una vez realizados los talleres de Cartografía Social Pedagógica (CSP) y analizada la información proveniente de las narraciones seleccionadas de profesores en ejercicio que cursan maestrías en el campo educativo, se encontraron ciertas regularidades que bien pueden entenderse como categorías emergentes. Estas son: teorización sobre CSP, pertenencia a un territorio existencial, posibilidades de la CSP en investigación y pedagogía, transformación de las prácticas y experiencia vital.

Cabe mencionar que en esta sección se intentará exaltar la percepción de los participantes para así fortalecer la idea subyacente en la CSP que sostiene que es posible producir conocimiento a partir de este ejercicio, la cual ha dado forma al horizonte teórico que se presentó en las primeras páginas de este trabajo.

\section{Teorización sobre csp}

Todos los participantes coinciden en que la CSP es una opción metodológica en la que, al participar de un colectivo, se puede configurar una forma de acceder a los fenómenos que acontecen en dicho grupo, trastocando una visión uniforme, estática, unívoca de la realidad: 
Este ejercicio lo asumí como una actividad "caricaturesca" pero en esa aparente diversión de la representación radica también su gran poder: la interpretación de lo individual a lo colectivo de la realidad. Cada quien cuenta su versión de los hechos y los reconstruye desde su experiencia de vida, o desde su perspectiva de conocimientos, sus valores, haciéndolo no sólo a través de la representación, sino a través del diálogo, de la discusión y de la concertación de los contenidos de aquello que se va a representar. Por otra parte al socializar con otros equipos de trabajo es mucho lo que se puede aprender. (TCSP 11, profesora 3)

De esta manera, el ejercicio cartográfico realizado permitió ir más allá de los usos cartográficos tradicionales y asumir los mapas de forma amplia, no solo como la descripción de un espacio físico, tal como se evidencia en el siguiente testimonio:

\section{[...] pude comprender} que la cartografía no solo sirve para representar en planos todos los componentes de un espacio, sino, que también puede ser utilizado [sic] como una herramienta para graficar las actividades $y$ desarrollos del hombre, lo que permitiría entender conceptos no muy claros de comprender. (TCSP 8, profesora 5)

Los participantes, salvo dos personas, no habían tenido la experiencia de cartografía social ni de cartografía participativa, asunto que se convirtió en motivo de expectativa y de oportunidad para configurar vivencialmente su percepción sobre la CSP:
Nunca había escuchado mencionar este tema, $y$ al trabajar en un campo desconocido me sentí siendo arrojado en un mundo nuevo donde se parte de cero, es decir, se eliminan los prejuicios y se comienza a crear un nuevo lenguaje, en este caso un lenguaje simbó- lico donde no existe nin- gún tipo de convenciones y estas deben establecerse por el grupo. (TCSP 5, pro- fesor 13)

Esta situación, antes de convertirse en una limitante, permitió que los diferentes participantes en la experiencia cartográfica pudiesen abrirse a nuevos horizontes de comprensión de lo participativo al realizar una cartografía con enfoque pedagógico y no solo desde el trabajo social o áreas afines: "de todas las experiencias de aprendizaje que he 
tenido esta fue la mejor. Había escuchado sobre el tema pero siempre pensé que era algo que solo se podía hacer en el área de sociales" (TCSP 8, profesora2). En estos términos, la oportunidad para indagar sobre las posibilidades de la CSP y su aplicabilidad en el campo de la educación resultó evidente, como lo manifiesta la reflexión siguiente:

[...] sin lugar a dudas la Cartografía Social Pedagógica demostró que la misma tiene lógica y sentido cuando se hace un ejercicio colectivo del entorno, desarrollando entre otras cosas, un lenguaje común de interpretación de las realidades de cada uno de los participantes; lo cual dio lugar, a generar espacios de reflexión para mejores saberes de la realidad que se estaba construyendo (educativa en este caso) y que obviamente está en constante evolución. (TCSP 13, profesor 20)

Tales percepciones llevaron a configurar, desde la vivencia de los participantes, una conceptualización sobre la CSP. A continuación, se muestran algunas propuestas que por su fuerza argumentativa, nacida de la experiencia, bien pueden tomarse como horizonte teórico de conceptualización que aporte a la configuración las características de la CSP:

Desde mi punto de vista la Cartografía Social Pedagógica se puede definir como un proceso didáctico que nos motiva al diálogo entre todos los actores presentes, nos lleva a la incorporación de categorías conceptuales pedagógicas de una manera más compleja, elaboración de estructuras conceptuales (mapas) de una forma creativa que nos contextualiza y generar visiones sobre nuestro entorno. Desde esta noción hermenéutica podemos realizar investigación en práctica pedagógica para la generación de conocimiento de un fenómeno social de vital importancia como lo es la educación en nuestro medio y llevar al mejoramiento de la calidad de este en nuestra comunidad. (TCSP 13, profesor 15)

La Cartografía Social Pedagógica brindó un espacio de interacción con los compañeros y un verdadero trabajo en equipo donde en el proceso de aprendizaje se partió del dialogo [sic]. [...] Es de gran valor reconocer cómo 
se discutió, se opinó y se dieron posibles soluciones al respecto, Ilegando a acuerdos sólidos que permitieran obtener buenos resultados. Escoger el tema para aplicarlo a la educación fue aventura ya que llevo [sic] al grupo a pensar en algo que fuera original, divertido y creativo. (TCSP 5, profesora 8)

Es un ejercicio bastante complejo donde se debe tener un buen conocimiento y una buena observación del objeto de estudio. La complejidad de la cartografía se plasma al conectar todos sus elementos o subsistemas representándolos gráficamente y así tener una comprensión de sus elementos y cómo interactúan entre sí. (TCSP 2, profesor 3)

La elaboración de la cartografía requiere de un trabajo organizado y su éxito, en gran medida, depende de las preguntas que orienten este trabajo, por lo tanto es muy importante que quienes se involucren en su elaboración, participen de un diálogo horizontal y del intercambio de ideas y percepciones. (TCSP 8, profesora 7)
Es un proceso dinámico, y participativo que nos permite acercarnos a la realidad social y educativa, que tiene en cuenta la participación de cada uno de los individuos que conforman el grupo de creación. En la Cartografía Social Pedagógica, se puede apreciar un producto social que es lo esencial en el conocimiento, a partir de ello se crea una relación de convivencia y trueque de ideas que circundan una realidad vivenciada, dejando como núcleo central la unión y el desarrollo de pensamiento e integralidad de una comunidad, o sociedad [...] es la evidencia observada en el diario vivir, la experiencia adquirida y compartida, la realidad circundante, la aceptación de ideas diversas y contradictoras, que empiezan a ser compartidas. (TCSP 10, profesora 14)

Como herramienta metodológica de trabajo, permite vincular a los integrantes de un grupo con cada una de sus particularidades, y lograr reflexiones sobre temas específicos. (TCSP 11, profesora 5) 
Los testimonios anteriores dan cuenta de un ejercicio serio de reflexión, en el que los participantes en los talleres pudieron asumir lo que significaba su experiencia y produjeron teoría alrededor de la CSP, al punto de proponer argumentos que permiten caracterizarla.

\section{Pertenencia a un territorio existencial}

Como se ha mostrado en el horizonte teórico de este trabajo, el tema del territorio resulta crucial en cualquier tipo de cartografía. En las narraciones que nos convocan este es un aspecto que aparece con notoria fuerza, ya que los participantes no mapeaban un territorio físico, sino que se adentraban en la complejidad de los territorios epistemológicos (de conocimiento) y los existenciales (de la vida misma). Así las cosas, las comprensiones sobre la CSP remiten a que es una ruta válida y poderosa para generar cambios significativos en un territorio, el cual, en el caso de este grupo en particular, no se circunscribe al lugar geográfico donde acontecen las relacione sociales. El territorio aquí toma dimensiones más amplias y se relaciona con los procesos educativos

La cartografía como estrategia metodológica me permite visualizar situaciones que generen cambios de mejoras en un territorio, en este caso nos centramos en la comunidad educativa. Una de las ventajas de esta estrategia es que en lugar de dar un informe narrativo que puede llenar a páginas y páginas, se puede mostrar de forma amena con un solo impacto visual. La Cartografía Social Pedagógica se podría convertir en catalizador de procesos de cambio, de intervención que encaminan estrategias colectivas de transformación social". (TCSP 11, profesora 4)

O como se expresa en estos testimonios:

Desde el ejercicio de hacer Cartografía Social, he podido romper paradigmas acerca de cómo leer el sistema educativo en el cual estamos inmersos, puesto que pude leer los problemas y ubicarlos dentro de una imagen o imágenes, en este caso, viendo el sistema como el universo del cual es imposible salirse, y ubicando así mismo como [sic] los actores (estudiantes, maestros, conocimiento, ciencia, hermenéutica, epistemología, método científico, razón, teoría, etc.) intervienen; y a su vez generan cambios o mantienen un orden. (TCSP 8, profesor 18) 
La Cartografía Social Pedagógica promueve una forma didáctica de encontrar regularidades en un espacio o en un territorio determinado, habitado por un grupo humano con el objetivo de obtener una participación de la comunidad con compromiso con miras de una transformación del mismo. (TCSP 11 , profesora 6 )
Me sentí bien, pues todas las compañeras aportamos nuestras ideas $y$ logramos el objetivo de realizar el mapa, considero que la cartografía es un excelente ejercicio con el cual podemos apropiarnos más de la realidad escolar y del contexto de nuestras instituciones educativas. (TCSP 10, profesora 10)

Figura 3. Ejemplo de mapas: territorios epistemológicos y territorio existencial (TCSP 5; TCSP 13)
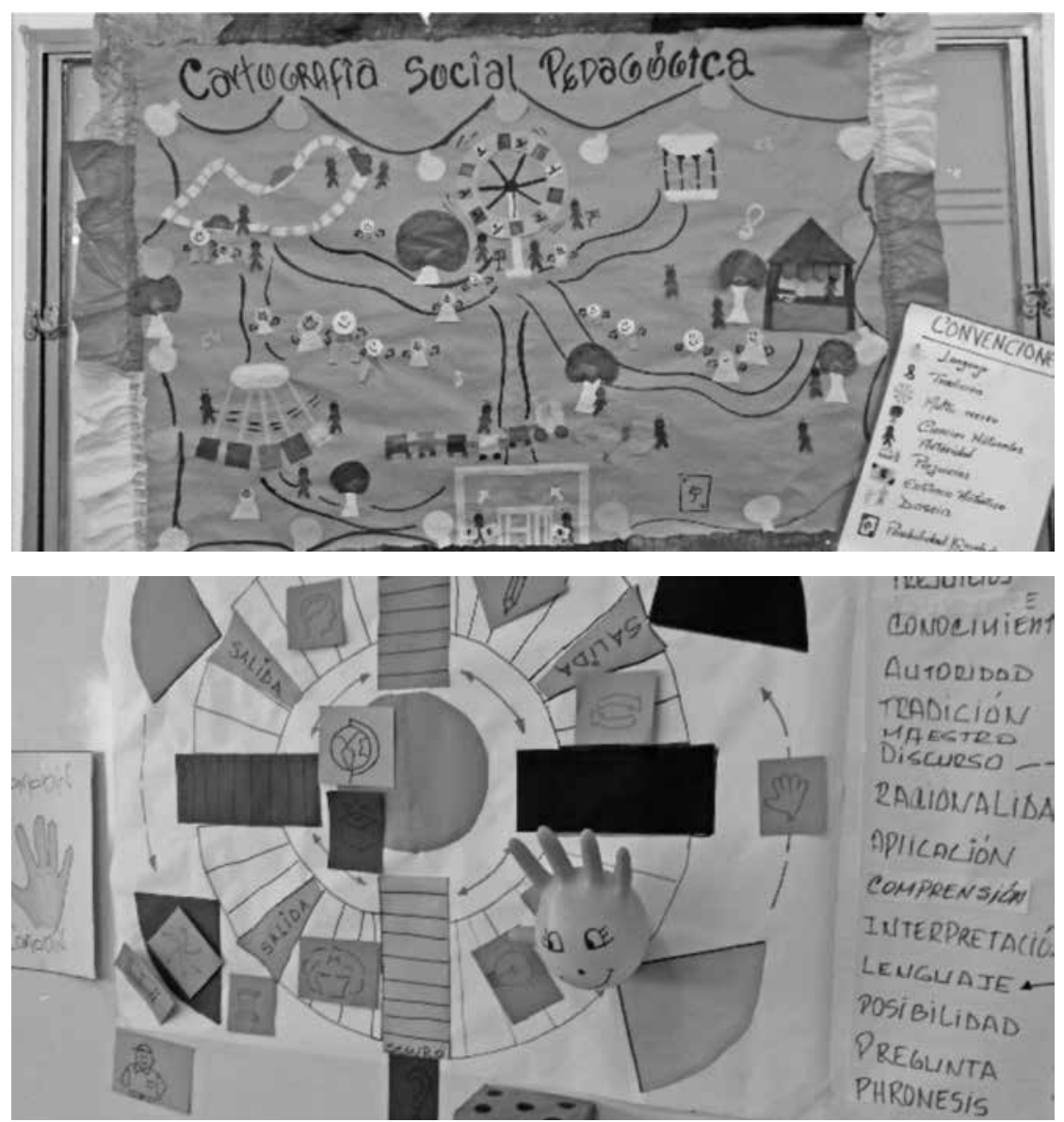
Por otra parte, se evidencia un tipo de la subjetivación en un territorio existencial que vincula el quehacer docente; es decir, un territorio que va más allá del simple conocimiento de las teorías pedagógicas:

Gadamer enfatiza que "El lenguaje es la primera etapa de la comprensión, que determina no solo el objeto sino la forma en que entendemos"; complementando lo anterior con la cartografía, y tomándola como una forma de ver la realidad de: ¿cómo vivo mi territorio como docente y cómo construyo el futuro territorio que deseo?, e integrando el trabajo realizado en clase por cada grupo, donde inicialmente fue complejo interpretar lo que decía cada convención; así, la pedagogía que implemento como maestra, debe cambiar la visión para que deje de ser un concepto confuso de autonomía y se convierta en instrumento de reflexión, de acción y posibilidades, proponiendo nuevas maneras de hacer educación. (TCSP 5, profesora 6)

Desde esta perspectiva, la pedagogía ya no puede reducirse a los asuntos teóricos que fundamentan las acciones, pues como territorio existencial permite configurar las representaciones de los procesos de enseñanza y aprendizaje en clave del papel humanizante del formador: "en especial me ayudó [el taller de CSP] a recordar que antes que docente soy humana y que depende de las practicas pedagógicas que yo emplee enseñar al niño el arte de saber vivir" (TCSP 14, profesora 22).

El territorio, entonces se transforma y este es tal vez uno de los aportes más importantes de la CSP a la cartografía social y a la cartografía participativa, que el territorio ya no se circunscribe al mapeo de realidades que acontecen en un espacio físico (el campo, la ciudad, el parque, la escuela, por ejemplo) sino que se vincula con toda forma de abstracción que es habitada por un grupo humano, rompiendo, incluso, con los cánones de tales cartografías. Así entonces, se rompe con lo hegemónicamente establecido sobre el conocimiento y la investigación social:

Tradicionalmente se ha entendido que la investigación sea en el campo de las ciencias naturales o en las ciencias del espíritu (sociales y humanas)- es simplemente aplicar un marco teórico a una realidad que se comprende como externa al sujeto. Sin embargo, con el trabajo cartográfico que realizamos en grupo, en el cual se tomó como campo de investigación un territorio epistemológico en el que se 
confrontaba: la filosofía, la ciencia y el trabajo de investigación etnográfica, se pudo reconocer que en la investigación el sujeto pone en juego sus intereses, sensaciones y horizontes de comprensión; es decir, la investigación no tiene como característica fundamental la neutralidad de un sujeto frente a un sujeto. Por otro lado, el trabajo colectivo nos condujo a reconocer las diferencias, los diferentes pareceres, opiniones $y$ visiones de mundo, de la ciencia y del hombre. No fue fácil, en principio, llegar a acuerdos sobre el territorio epistemológico que íbamos a investigar, ni las convenciones que íbamos a utilizar, pero una vez fueron resueltas estas tareas el mapeo fue más fácil de llevar a cabo. (TCSP 10 , profesor 6 )

\section{Posibilidades de la CSP en investigación y pedagogía}

Para los profesores participantes en los talleres de csp fue muy significativo el poder ver las posibles aplicaciones de lo experimentado: "significó evidenciar que existen otras maneras de observar, analizar, interpretar y expresar contextos y realidades. Es un proceso de aprendizaje, una herramienta que per- mite generar estrategias pedagógicas desde la lúdica hasta la rigurosidad que exige la investigación" (TCSP 14, profesor 9). Dos tendencias emergieron con significativa fuerza; la primera se da en relación con usos didácticos y pedagógicos de la CSP:

La cartografía aplicada a la pedagogía se puede convertir en una herramienta importante para el desarrollo de las competencias en los estudiantes. En una primera aplicación se puede utilizar para la apropiación de conceptos y el afianzamiento de conocimientos alrededor de un saber porque pone a prueba en el estudiante su capacidad para comprender, analizar, sintetizar información y el desarrollo del pensamiento crítico. Por otro lado estimula la creatividad porque lleva al participante a recrear el conocimiento para demostrar su nivel de apropiación. Además se puede convertir en una excelente estrategia de evaluación porque brinda la posibilidad de que sus participantes entren en una relación profunda que permite el intercambio de saberes y la medición de los niveles de comprensión y aprendizaje. (TCSP 14 , profesor 16) 
Diseñar una planificación educativa apoyada en la cartografía me proporcionó herramientas dirigidas hacia calidad de las enseñanzas pedagógicas que me favorezcan en la praxis. La cartografía era algo que desconocía y me permitió aplicar técnicas acerca de lo importante y útil para mi desempeño como docente. (TCSP 14, profesora 6)

Los mapas cartográficos como uso pedagógico en la educación, desentrañan en el binomio docente-dicente la capacidad productiva de invención, que poseen; inventiva que permite que se plasme a través de la cartografía, críticas y propuestas del quehacer educativo, generándose conclusiones que permitirán reorientar el modelo de enseñanza- aprendizaje y reformularse la didáctica pedagógica utilizada. (TCSP 13, profesor 27)

Figura 4. Ejemplo de convenciones y mapa (TCSP 8 y TCSP 10)
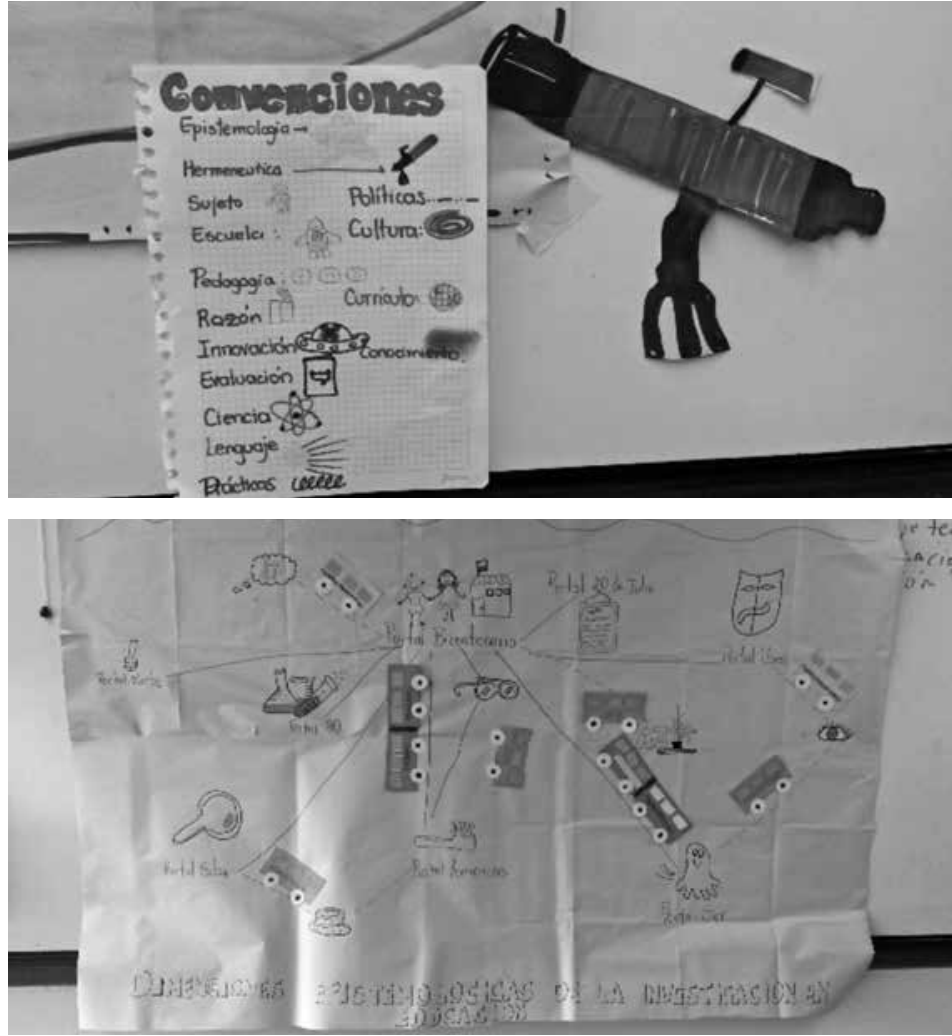
En esta misma línea de subjetivación, profesores de diversas áreas ven en la CSP una oportunidad para apoyar su ejercicio docente mejorando su didáctica: "muy buena actividad, excelente herramienta para replicar con nuestros estudiantes del programa de Derecho" (TCSP 13, profesora 24). También, otra maestra dice: "visualizando mi práctica como maestra de química, veo que son necesarios algunos cambios que están limitados por los contenidos de las asignaturas, y en general por los modelos pedagógicos, establecidos en las instituciones educativas" (TCSP 5, profesora 6); otra maestra afirma:

[...] a futuro, espero poner en práctica este método en mis clases, para hacer en mis asignaturas, un ambiente más agradable para aprender. Como dicto matemática, soy consciente de que mis alumnos manejan un alto grado de estrés, y este método es ideal para que aprendan no sólo a trabajar un concepto en equipo, sino también para afianzar conocimientos y pasarla bien. (TCSP 12, profesora 5)

Una trabajadora social que había realizado intervención con cartografía social y es profesora universitaria afirma:

[...] en esta oportunidad para la aplicación de la clase se hizo un poco difí- cil porque trabajar la cartografía desde una mirada desde la pedagogía pues fue de un solo concepto y desde ahí buscar la relación de este con otros que Ileven a entender su significado. (TCSP 14, profesora 4)

La segunda tendencia se relaciona con la pertinencia de la csp como recurso investigativo en lo relacionado con las metodologías o con el ser del profesor que se asoma al ejercicio investigativo: "el docente investigador debe emplear nuevas formas de acercarse al territorio de investigación, esto se puede lograr a través de la Cartografía Social Pedagógica" (тCSP 8, profesora 25). También, en relación con los procesos de los estudiantes: "[la CSP] permite identificar metodologías que pueden ser acertadas al punto de crítica e información de las capacidades intelectuales de cada uno de sus estudiantes investigadores" (TCSP 13, profesora 8), para así configurarse como investigador: "considero que me ha de servir enormemente en mi trabajo como investigador social" (TCSP 8, profesor 4). Con este marco de referencia, las posibilidades investigativas de la CSP cobran especial relevancia en este grupo de profesores que se forman a nivel posgradual, al punto de presentarse como una de las regularidades más fuertes dentro del proceso de análisis de la información de la presente investigación: 
Esta herramienta de trabajo [la CSP] en la investigación hace que el investigador se acerque a su objeto de estudio, es decir, hace que se aproxime al cambio de oyente y de autor del conocimiento, para que los diferentes grupos sociales de ese territorio intercambien ideas y percepciones, que luego serán interpretadas por el investigador. (TCSP 10, profesora 21)

Desde el aula de clases los docentes la podemos emplear [la CSP], para ahondar en la realidad social del grupo de estudiantes a los cuales acompañamos; es una estrategia que posibilita trabajar de diferentes maneras siempre y cuando seamos creativos y recursivos al utilizar la información. (TCSP 4, profesora 3)

Conocimos, que con este tipo de cartografía se realizan mapas sociales, que con ellos se facilita delimitar el espacio físico de la investigación (lugar habitado por un grupo humano). (TCSP 11, profesora 1)

Descubrir que el maestro es investigador y que sus escritos están basados en su quehacer, en sus prácticas de día a día, y que esto de cambiar de paradigma precisamente busca que uno así mismo se conciba como investigador, pero un investigador que tome y asuma riesgos por fuera del conocido método científico aplicado a desde las ciencias naturales a todas las demás ciencias incluyendo las humanidades y ciencias sociales. (TCSP 8, profesor 18)

En mi rol como docente-tutor veo la Cartografía Social Pedagógica, como una herramienta de trabajo que nos permite realizar diferentes acciones en nuestras prácticas de aula. La podemos utilizar con nuestros estudiantes para hacer investigación sobre algún acontecimiento en particular (identificar las tradiciones de algún lugar, conocer los imaginarios de algo) como herramienta evaluativa permite realizar una representación gráfica y sintetizada de algún tema, libro, realidad o suceso. (TCSP 14, profesor 15)

Realizar el ejercicio de la Cartografía Social Pedagógica me permitió complementar la contextualización de los conceptos abordados en clase y establecer unas 
conexiones entre estos

y las particularidades

en que se pueden hacer

investigaciones de índole educativo [sic]. (TCSP 10,

profesor 28)

\section{Transformación de las prácticas}

Lo expuesto solo tiene sentido en la medida en que la CSP impacta directamente a los actores de la misma, en relación con la transformación de las prácticas. En estos términos, todos los participantes en los talleres reconocieron que por esta vía de acercamiento a sus territorios existenciales como profesores se puede afectar su quehacer educativo: "fue el trabajo que más me agradó de los que hicimos pues desde algo tan simple se llega a cosas muy complejas y además me aporta una nueva idea para poder aplicarlo en mi practica pedagógica" (TCSP 10, profesora 16). Para los participantes se convirtió la CSP en la posibilidad de pensar y ver el espacio de aula de otra forma: "la experiencia vivida con la cartografía pedagógica nos da la oportunidad de mirar de una forma diferente los procesos de aula y generar distintas metodologías en las cuales el alumno sea protagonista dentro del desarrollo de productos basados en la temática propuesta" (TCSP 13, profesor 5). De tal manera, que se articula también a comprensiones de currículo: "en términos generales considero que el ejercicio fue enriquecedor, particu- larmente logré realizar vínculos con mi práctica pedagógica engranando la cartografía como una alternativa para la interpretación y apropiación de varios temas del currículo de las asignaturas que dirijo" (TCSP 11, profesora 5); de prácticas sobre inclusión: "además como docente de infantes y de personas con N. E. E. (necesidades educativas especiales) lo observo como un recurso accesible a esta población porque son quienes aprenden más con lo visual, lo gráfico, lo concreto podría ser adaptado según las necesidades e intereses del educando" (TCSP 11, profesora 6); sobre didácticas más allá de los temas sociales: "como docente de matemáticas me di la oportunidad de realizar este ejercicio con mis estudiantes, abordando el concepto de área, ya que es uno de los temas más relevantes en las pruebas nacionales y comprendí la importancia de analizar las diferentes vías en que los educandos asimilan dicho conocimiento" (TCSP 10, profesor 19); como también prácticas en el ámbito del preescolar: "esta experiencia me dejó muy satisfecha a nivel personal, y me queda la inquietud, para ponerla en práctica con mis estudiantes de forma lúdica e innovadora, a pesar de la corta edad que tienen, veo que lo puedo adecuar a ellos" (TCSP 11, profesora 1).

La modificación de las prácticas se convierten en el centro y eje de la CSP, de tal suerte que los profesores constituyen su subjetividad como profesionales de la educación y necesariamente se asume la auténtica 
transformación educativa y el empoderamiento como agentes de transformación social en educación a través de nuevas formas de practicar las relaciones entre enseñanza y aprendizaje:

[...] me permitió, junto a los compañeros de mi grupo, construir conocimiento integral para reconstruir nuestro aprender a través de la Cartografía Social, desplegada en el ámbito de las prácticas pedagógicas [...]. Debemos esforzarnos al máximo por cambiar nuestras prácticas pedagógicas aburridas y arcaicas, hacerlas modernas, actuales, tanto en contenidos como en lo práctico, evolucionando en el paso a paso que conlleva la modernidad y hacer un diagnóstico pedagógico para llevar a un pronóstico hermenéutico significativo y la Cartografía Social Pedagógica me contribuyó a repensar lo aprendido. (TCSP 5, profesora 7)

El diseño estructural de una Cartografía Social Pedagógica permite al docente ahondar en dimensiones que el docente en su práctica cotidiana puede reconocer, mas no analizar de forma tan clara. El diseño de esta herramienta permite trazar derroteros que guían y orientan la actividad pedagógica en pos no solo del mejoramiento del proceso de enseñar y aprender, sino también, de la formación integral del sujeto educado. En tal sentido, es importante que el maestro entienda que esta cartografía es en sí un proceso de reflexión de su labor diaria, y si bien es cierto, debe estar abierto a recibir modificaciones propias de la impredecible relación constante entre docente y estudiante, también lo es que esta requiere una concientización respecto de fallas y aciertos dentro de la práctica pedagógica. Esto en el entendido de que no se consigue nada con el simple hecho de realizar la cartografía si no cumple su fin ulterior, el cual es servir de apoyo al docente, pero también al estudiante, en el arduo camino de la formación tanto académica como integral. (TCSP 5, profesora 8) 


\section{Experiencia vital}

Asumir la existencia implica experimentar vitalmente lo que acontece; por ello, los talleres de cSP impactaron sustancialmente a los participantes. Ellos, al ser profesores en ejercicio y estar como estudiantes en un nivel de maestría, normalmente encuentran que las actividades formativas de sus profesores son planas, acartonadas y monótonas: clase magistrales, lecturas académicas, discusión de las mismas, exposiciones, por solo citar algunas estrategias que son comunes en programas de posgrado. Contrario a esto, las actividades de cSP permitieron el goce y disfrute de los participantes cuando las realizaban: "el hecho de aplicar la cartografía significó para mí una oportunidad muy grande para movilizar procesos mentales que rompen la manera tradicional de acercarse a un tema o a una situación particular" (TCSP 14, profesora 10); especialmente cuando este profesor afirma: "el ejercicio de

Figura 5. Actividad de los participantes (TCSP 2; TCSP 14)
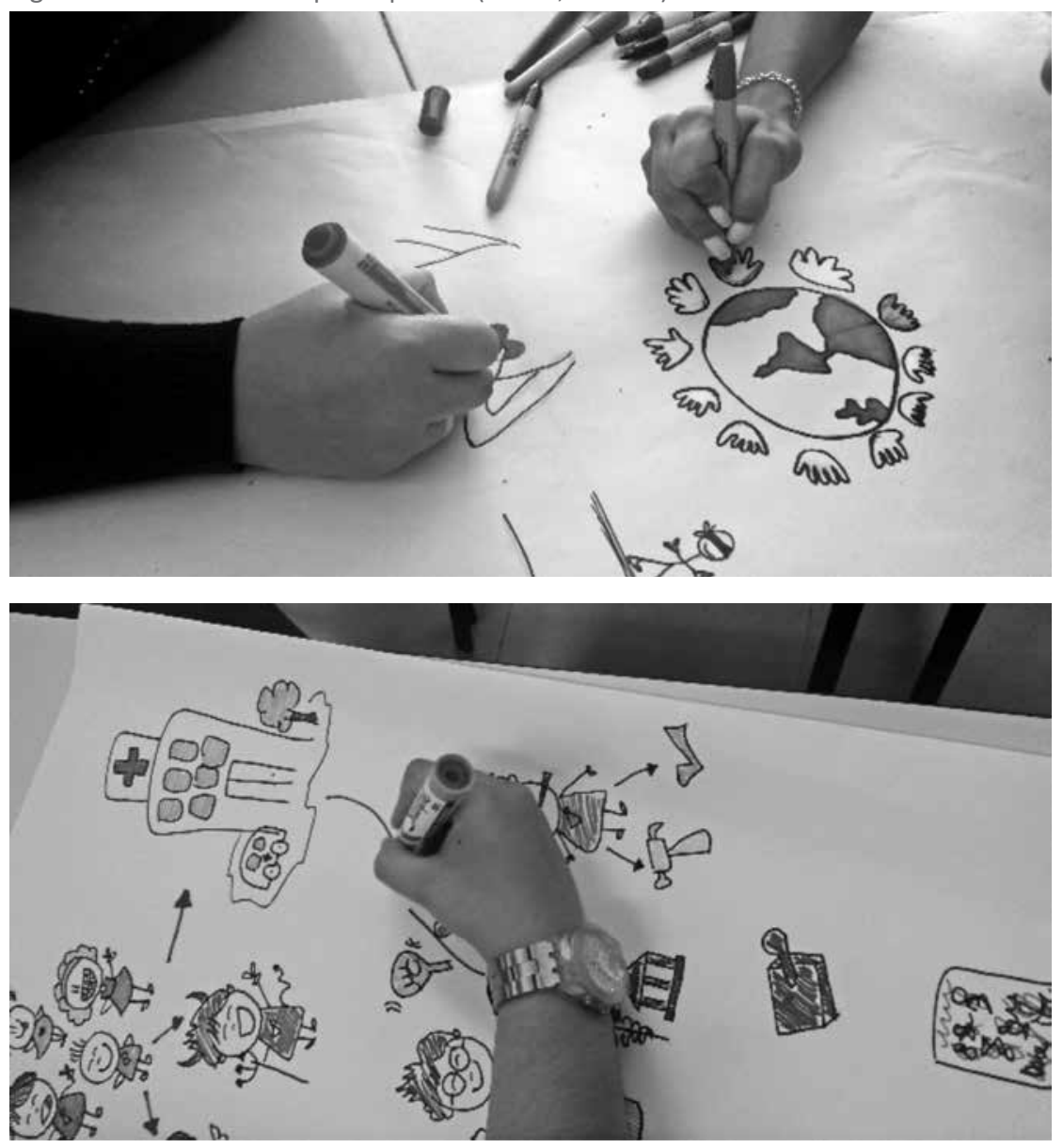
hacer cartografía me pareció muy divertido, permitió un buen trabajo en equipo, donde todos aportaron para que el trabajo estuviera bien realizado" (TCSP 10, profesor 2).

A la vez aparece el otro como experiencia vital que interpela y es un par con quien se construyen asuntos colectivos: "Fue una experiencia maravillosa pues no había trabajado esta metodología de Cartografía Social Pedagógica ni en el pregrado ni en la especialización, gracias por permitirnos realizar esta práctica pedagógica diferente, motivándonos a ser mejores docentes y a desarrollar nuestro pensamiento y creatividad al máximo" (TCSP 5, profesora 17)", pares que en todo caso configuran un horizonte social de subjetivación como profesores: "fue un ejercicio enriquecedor porque permitió la interacción con los compañeros, favoreciendo la expresión de las opiniones y la creación de acuerdos para poder representar las ideas de todos los miembros del grupo" (TCSP 14, profesora 10) y también: "fue una experiencia nueva ya que no sabía que se podía hacer Cartografía Social Pedagógica; me pareció un excelente ejercicio en la medida en que nos unió como grupo, para determinar conceptos y convenciones fue necesario escucharnos unos a otros y ponernos de acuerdo, por otra parte fue una nueva forma de sintetizar contenidos, extraer las ideas más importantes de un tema y explicarlo mediante imágenes" (TCSP 12, profesora 7).

Estas afirmaciones llevan a pensar sobre la constitución de subjetividad de los participantes, quienes, como sujetos activos dentro de los procesos de enseñanza y aprendizaje se reconocen como actores que se empoderan alrededor de sus prácticas:

Para concluir, me parece que el ejercicio del mapeo, no solo fortalece la parte conceptual del curso, sino que apunta a otros aspectos que son importantes como el trabajo en equipo, el diálogo, la sensibilidad, la interpretación y el valorar y respetar el trabajo y la opinión (así no se esté de acuerdo) de los demás. (TCSP 10, profesora 18)

Culmino este escrito mencionando que si es posible cambiar paradigmas y hacer trabajo de alta producción, no solo bastó leer un libro, entenderlo y hacerlo práctico fue lo mejor, saber que se puede mejorar desde lo particular, es innovar y a eso debemos apuntar si nuestro propósito es sobresalir en un mundo laboral competitivo. (TCSP 8, profesor 21) 
Confieso que es la primera vez que trabajo este tipo de herramienta, había escuchado hablar de ella pero no había tenido la oportunidad de trabajarla, me pareció interesante por cuanto me considero una persona muy visual, como mecanismo de exploración para investigación llama mucho mi atención sobre todo para trabajos de tipo social. (TCSP 13, profesora 2)

Hacer este primer ejercicio de cartografía fue para mí una experiencia pedagógica totalmente distinta; durante el ejercicio realizado pude experimentar que hacer cartografía implica más que un buen conocimiento del tema, que trabajar en ella requiere también de muy buena imaginación y creatividad para poder transmitir fácilmente las ideas de manera clara y sencilla a toda clase de receptor. (TCSP 13, profesora 22)

Maestros que reconocen su ahí existencial fueron los que aparecieron en estas narraciones, especialmente porque su experiencia con la CSP fue vital y les permitió asumirse más allá de su ser profesional y encajar como colectividad.

\section{Conclusiones y prospectiva}

Con base en lo analizado, propiamente el aporte de este estudio para configuración del corpus teórico y metodológico de la CSP, se puede sintetizar en los aspectos siguientes:

\section{Respecto a lo teórico}

Es posible configurar teoría educativa partiendo de las prácticas, en este caso los talleres de CSP; así, todos los participantes en la investigación reconocieron la pertinencia e importancia de la CSP para transformar las prácticas y la gran mayoría evidenciaron interés de replicar la estrategia en el pedagógico y, ocasionalmente, en el investigativo. Esto se evidencia en que las opiniones de los profesores del estudio se orientan más a la aplicación de la cartografía en el aula, que a su empleo en sus ejercicios investigativos.

En la csp la concepción de territorio puede trascender lo físico, por ello se exploran territorios epistemológicos, que tienen que ver con las condiciones de producción de conocimiento y territorios existenciales, en los que se escudriñan las vivencias ontológicas de los seres humanos. Estos territorios fundan relaciones en el campo de los procesos de enseñanza-aprendizaje y otros campos del saber.

Más allá de la teorización, los usos pedagógicos e investigativos, la cSP posibilita la constitución de subjetividad de los participantes al punto de permitir una experiencia vital en la que cada cual reconoce a los otros como pares. 
En la CSP emerge un nivel hermenéutico que sobrepasa la simple intelección y se inscribe la aplicación (práctica), que debe explorarse y desarrollarse. En esta medida, es importante continuar la investigación sobre las dimensiones ontológicas de esta estrategia metodológica.

La cartografía participativa y la cartografía social son herramientas poderosas para la intervención e investigación social, pero su uso en el campo de la educación es aún limitado.

La CSP intenta romper los esquemas hegemónicos frente a la investigación educativa, por ello necesita configurar nuevas categorías comprensivas, pues su centro está en la acción reflexiva.

La CSP toma elementos de la cartografía participativa y la cartografía social y los aplica al campo educativo, complementando los desarrollos de estos dos tipos de cartografías. Así, la CSP se erige como una estrategia metodológica que permite abordar problemáticas educativas configurando nuevos campos de indagación e intervención.

La CSP intenta romper los esquemas hegemónicos frente a la investigación educativa, por ello necesita configurar nuevas categorías comprensivas, pues su centro está en la acción reflexiva.

Por su componente participativo centrado en el actuar, la CSP lleva a empoderar a los participantes para configurar lazos de pertenencia a una colectividad o a formas de comprender la educación. En ese proceso se configuran los territorios de pertenencia de los actores educativos, que en el caso de esta investigación fueron profesores en ejercicio que cursaban maestrías en el campo de la educación.

Por ser un naciente campo de indagación, la csp fácilmente puede desdibujarse de su nivel investigativo, por ello debe seguirse configurando su corpus teórico y de prácticas rigurosas para así fortalecer sus procedimientos, fundamentos y posibilidades, en términos pedagógicos, investigativos y de intervención.

\section{Respecto a lo metodológico}

Los pasos propuestos por Barragán y Amador (2014) para la realización de cartografía social pedagógica (selección del tipo de problemática, selección del tipo de mapa, motivación de los participantes, grupos de trabajo, acuerdo de convenciones, elaboración del mapa, explicación del mapa, acuerdos de transformación, análisis de los mapas y memoria de la cartografía) permiten desarrollar CSP eficazmente y fueron validados en los 14 talleres en los que participaron 313 estudiantes de posgrado. 
Estos pasos se proponen como ruta de configuración de la CSP, y como una estrategia particular, ejercicios de CSP en educación y pedagogía.

La CSP en cuanto ruta emergente de investigación cualitativa puede utilizarse como opción metodológica de investigación en educación y pedagogía.

Además de las implicaciones investigativas, la CSP abre horizontes didácticos que permiten resignificar las prácticas de diversos actores educativos. Como estrategia didáctica, lleva a la innovación y a la transformación de las prácticas.

\section{Referencias bibliográficas}

Advancement Project-Healthy City. (2012, abril). Participatory Asset Mapping. Disponible en: http:// www.advancementprojectca.org/ Alcaldía Mayor de Bogotá, D. C. (2008). Cartografía social. Cartografiando nuestra realidad. Bogotá: Alcaldía Mayor de Bogotá-Fundación Arco Iris.

Álvarez, D.; Braida, F.; Carbajal, J.; Coiana, N.; Dagnino, R.; D’Angelo, G.; Wyzcynsky, E. (2011). Cartografía social del entorno geográfico de la Facultad de Ciencias. En M. Pérez, \& A. Cano (eds.), Laboratorio barrial de experiencias. Programa integral metropolitano (pp. 12-31). Montevideo: Universidad de la República.
Barragán, D. (2012). Subjetividad hermenéutica. Su constitución a partir de las categorías memoria, utopía, narración y auto-comprensión. Bogotá: Cinde.

Barragán, D. (2013). Cibercultura y prácticas de los profesores. Entre hermenéutica y educación. Bogotá: Universidad de La Salle. Barragán, D. (2015). Las comunidades de práctica (cp): hacia una reconfiguración hermenéutica. Franciscanum, 57 (163), 139-165.

Barragán, D. \& Amador, J. C. (2014). La cartografía social-pedagógica: una oportunidad para producir conocimento y repensar la educación. Itinerario Educativo 64.

Bernal, R. \& Galindo, D. (2012). Cartografía social y sistemas de información geográfica. Una nueva experiencia en la educación. Revista Digital del Grupo de Estudios sobre Geografía y Análisis Espacial con Sistemas de Información Geográfica (Gesig) (4), 169-186.

Berno de Almeida, A. \& Acevedo, R. (eds.). (2010). Nova Cartografia Social dos Povos e Comunidades Tradicionais do Brasil: Povo Indígena. Manaus: uea Edições.

Braceras, I. (2012, septiembre). Cartografía participativa: herramienta de empoderamiento y de participación por el derecho al territorio. Trabajo de fin de máster. Instituto de Estudios sobre Desarrollo y Cooperación Internacional. Universidad del país Vasco. Disponible en: http://biblioteca. hegoa.ehu.es/registros/19416 
Carballeda, A. (2012). Cartografías e intervención en lo social. En J. M. Diez Tetamanti, \& E. Beatriz (eds.). Cartografía social. Investigación e intervención desde las ciencias sociales, métodos y experiencias (pp. 27-36). Comodoro Rivadavia: Universidad de la Patagonia.

Carr, W. (2004). Philosophy and Education. Journal of Philosophy of Education, 28 (1), 56-73.

Carr, W. (2007). El docente investigador en educación. Textos de Wilfred Carr. (A. Méndez \& S. Méndez, eds.) Chiapas: Universidad de Ciencias y Artes de Chiapas.

Centro de Estudios Sociales. (2011). Tierra y derechos en aguas turbulentas. Aportes metodológicos para la construcción de cartografías sociales. Bogotá: Universidad Nacional de Colombia.

Chambers, R. (2006). El mapeo participativo y los sistemas de información geográfica: ¿de quién son los mapas? ¿quién se empodera y quién se desempodera? ¿quién gana y quién pierde? EISDC, 25 (2), 1-12.

Creswell, J. (1997). Qualitative inquiry and research design: choosing among five traditions. California: Sage Publications.

Diez Tetamanti, J. M. (2012). Cartografía social. Herramienta de intervención e investigación social compleja. El vertebramiento inercial como proceso mapeado. En J. M. Diez Tetamanti, \& B. Escudero (eds.), Cartografía social. Investigación e intervención desde las ciencias sociales, métodos y experiencias (pp. 13-24). Comodoro Rivadavia: Universidad de la Patagonia.

Escudero, A. B. (2012). Taquigrafías de un territorio: espacio, tiempo y lugar. En J. M. Diez Tetamanti \& B. Escudero (eds.), Cartografía Social. Investigación e intervención desde las ciencias sociales, métodos y experiencias (págs. 53-68). Comodoro Rivadavia: Universidad de la Patagonia.

Fondo Internacional de Desarrollo Agrícola. (2009). Buenas prácticas en cartografía participativa. Análisis preparado para el Fondo Internacional de Desarrollo Agrícola (fida). Roma: Autor.

Fox, J.; Suryanata, K. \& Hershock, P. (eds.). (2005). Mapping communities. Ethics, values, practice. Honolulu, Hawaii: East-West Center.

Gabbert, W. (2006, abril). Concepts of ethnicity. Latin American and Caribbean Studies, 1 (1), 85-103.

Galeano, E. (2003). Nosotros decimos no (crónicas 1963-1988). Madrid: Siglo XxI editores. 
Galeano, M. E. (2009). Estrategias de investigación social cualitativa. El giro de la mirada. Medellín: La Carreta.

García, M. (2012, julio-diciembre). La violencia intrafamiliar: una problemática que requiere pensarse desde lo interinstitucional. Eleuthera, 7, 90-103.

Guattari, F. (1996). Caosmosis. Buenos Aires: Manantial.

Guattari, F. (2000). Las tres ecologías. Valencia: Pre-textos.

Habegger, S. (2008, abril). La cartografía del territorio como práctica participativa de resistencia: Procesos en metodologías implicativas, dispositivos visuales y mediación pedagógica para la transformación social. Tesis doctoral. Repositorio institucional de la Universidad de la Málaga. Disponible en: http://riuma.uma. es/xmlui/handle/10630/2555

Habegger, S.; Serrano, E. \& Mancila, I. (2006). El poder de la cartografía del territorio en las prácticas contrahegemónicas. Quaderns d'Educació Contínua, 15.

Hallak, Z. \& Barberena, M. (2012). Herramienta de intervención profesional y de aprendizajes en trabajo social. En J. M. Diez Tetamanti \& B. Escudero (eds.), Cartografía Social. Investigación e intervención desde las ciencias sociales, métodos y experiencias (pp. 71-92). Comodoro Rivadavia: Universidad de la Patagonia.
Harley, J. B. (2005). La nueva naturaleza de los mapas. Ensayos sobre la historia de la cartografía. México: FCE.

Hristova, D.; Quattrone, G.; Mashhadi, A. \& Capra, L. (2013, junio 28). The life of the party: Impact of social mapping in OpenStreetMap. Association for the Advancement of Artificial. Intelligence: https://www.aaai.org/ocs/ index.php/ICWSM/ICWSM13/paper/ view/6098

Huberman, M. \& Miles, M. (1991). Analyse des donnés qualitatives. Bruxelles: De Boeeck.

Kirk, G.; Raven, J. \& Schofield, M. (2014). Los filósofos presocráticos. Historia crítica con selección de textos. (J. García Fernández, trad.) Madrid: Gredos.

Krippendorf, K. (1990). Metodología de análisis de contenido. Teoría y práctica. Barcelona: Paidós.

Montoya, V. (2007, enero-junio). El mapa de lo invisible. Silencios y gramática del poder en la cartografía. Revista Universitas Humanística, 63, 155-179.

Montoya, V.; García, A. \& Ospina, C. (2013, abril). Andar dibujando y dibujar andando: cartografía social y producción colectiva de conocimientos. Nómadas 40, 191-205.

Mora-Páez, H. \& Jaramillo, C. (2004, enero-junio). Aproximación a la construcción de cartografía social a través de la geomática. Ventana Informática, 11, 129-146. 
Movimento Interestadual das Quebradeiras de Coco Babaçu. (2005). Nova Cartografi a Social da Amazônia. Fascículo 5. Quebradeiras de coco babaçu do Pará. São Luís.

Navarro, P. \& Díaz, C. (1999). Análisis de contenido. En J. M. Delgado, \& J. Gutiérrez, Métodos y técnicas cualitativas de investigación en ciencias sociales (pp. 177-244). Madrid: Síntesis.

Organización Internacional para las Migraciones. (2009). Mapas de vulnerabilidad, riesgos y oportunidades (MVRO). Bogotá: Organización Internacional para las Migraciones (OIM).

Osorio, H. \& Rojas, E. (2011, diciembre). La cartografía como medio investigativo y pedagógico. Dearq, 9, 30-47.

Quiñónez, M. C. (2011, julio-diciembre). La manera cultural: Entre el desarraigo y la territorialización - Una experiencia de cartografía social en la zona de bajamar - Isla de Cascajal Buenaventura. Entramado, 7 (2), 156-171.

Rambaldi, G. (2005). Who Owns the Map Legend? URISA, Journal of the Urban and Regional Information Systems Association, $17(1), 5-13$.

Sampaio, M. A. (2012). Geografias do dissenso: sobre conflitos, justiça ambiental e cartografia social no Brasil. Espaço e ECOnomia. Revista Brasileira de Geografia Econômica, 1 (1), 1-13.

Santos, B. D. (2010). Para descolonizar Occidente. Más allá del pensamiento abismal. Buenos Aires: Clacso.

Stromquist, N. (2006). Una cartografía social del género en la educación. Educación Social, 27 (95), 361-383.

United Nations Human Settlements Programme. (2010). Volume 3: Community mapping guide. A youth community mapping toolkit for East Africa. Nairobi, Kenia: Autor.

Valderrama, R. (2013). Diagnóstico participativo con cartografía social. Innovaciones en metodología investigación-acción participativa (IAP). Anduli. Revista Andaluza de Ciencias Sociales, 12, 53-64.

Vázquez, A. \& Massera, C. (2012). Repensando la geografía aplicada a partir de la cartografía social. En J. M. Diez Tetamanti, \& B. Escudero (eds.), Cartografía Social. Investigación e intervención desde las ciencias sociales, métodos y experiencias (pp. 95-107). Comodoro Rivadavia: Universidad de la Patagonia. 
Vélez, I.; Rátiva, S. \& Valera, V. Vicepresidencia de la República. (2012). Cartografía social como (2010). Cartografía social indímetodología participativa y gena del departamento del Meta. colaborativa de investigación Restrepo: Vicepresidencia de la en el territorio afrodescendiente República de Colombia.

de la cuenca alta del río Cauca. Walsh, C. (2007). Interculturalidad, Cuadernos de Geografía. Revista colonialidad y educación. EduColombiana de Geografía, 21 (2), 59-73. cación y Pedagogía, 19 (48), 25-35. 